\title{
AN APPLICATION OF THE TODIM METHOD TO THE EVALUATION OF BROADBAND INTERNET PLANS
}

\author{
Luís Alberto Duncan Rangel ${ }^{1}$, Luiz Flavio Autran Monteiro Gomes ${ }^{2 *}$ \\ and Felipe Parussoli Cardoso ${ }^{3}$
}

Received November 19, 2009 / Accepted October 28, 2010

\begin{abstract}
This article presents a case study of the evaluation of the various types of access to the Broadband Internet available to a small company, located in Volta Redonda, in the state of Rio de Janeiro. This small company needs to implement Broadband Internet in its establishment and sought an evaluation of the companies which work providing this type of service. With the aim of carrying out a technical evaluation of the provision of the Broadband Internet service and, considering the diverse points of view and needs of this small company, a Multicriteria Decision Aiding Method, the TODIM method, was used. By means of this research, the power of this Operational Research tool was verified in the search for the solution to the problem of ranking the services offered in the city, according to the criteria chosen by this small company.
\end{abstract}

Keywords: Multicriteria Decision Aiding, Prospect Theory, Broadband Internet.

\section{INTRODUCTION}

This article presents the research carried out to verify the use of a Multicriteria Decision Aiding (MCDA) method in the evaluation of Broadband Internet access providers in the city of Volta Redonda, situated in the state of Rio de Janeiro. MCDA methods are used in diverse cases where there are numerous alternatives to be evaluated according to multiple qualitative and quantitative criteria. In this research, the various plans of Broadband Internet access offered by the providers of this type of service were considered as the alternatives. Meanwhile, the criteria were defined by the small company in need of this type of service.

\footnotetext{
*Corresponding author

${ }^{1}$ Universidade Federal Fluminense, Av. dos Trabalhadores, 420, Vila Santa Cecília, 27255-125 Volta Redonda, RJ, Brazil. E-mail: duncan@metal.eeimvr.uff.br

2 Ibmec/RJ, Av. Presidente Wilson, 118, sala 1110, Centro, 20030-020 Rio de Janeiro, RJ, Brazil.

E-mail: autran@ibmecrj.br

${ }^{3}$ Universidade Federal Fluminense, Av. dos Trabalhadores, 420, Vila Santa Cecília, 27255-125 Volta Redonda, RJ, Brazil. E-mail: fparussoli@vm.uff.br
} 
There are various methods which can be applied to the ranking of an MCDA problem. In this article the TODIM method (Gomes \& Lima, 1992a; 1992b; Gomes \& Rangel, 2009a) was used to evaluate the diverse alternatives that the market offers in terms of the service of Broadband Internet access which this small company could contract with the aim of meeting its requirements for this type of service.

The TODIM method has been used in various recent research articles and publications (Gomes, Araya \& Carignano, 2004; Gomes \& Rangel, 2009a; Gomes, Rangel \& Maranhão, 2009), among others. It is an MCDA method capable of ranking the alternatives according to the preferences of the decision makers. For this purpose, it incorporates Prospect Theory (Kahneman \& Tversky, 1979) in its formulation which considers aversion and propensity to risk during the decision making process. The method incorporates in its formulation characteristics of the French School, carrying out pair comparisons of the alternatives, and characteristics of the American School, through the global value function.

In this study, the TODIM method was used to rank alternatives of Broadband Internet access plans, which were selected from among those available in the city of Volta Redonda, in the state of Rio de Janeiro. After this ranking, it will be easier to define the type of plan to contract and from which company.

Nowadays, the internet is present in our day-to-day lives in society. It is even more present in the daily routine of companies and in the way they carry out their business. The interconnection brought by the Internet has made the world of business more dynamic. Broadband Internet is a relatively recent technology, although its benefits are so great that it is already present in the majority of businesses.

The development of the market of Broadband Internet provision has been accompanied by a great variety of offers of access technologies and also service providers, in additional to the increasing demand of the consumer market. These characteristics mean that this niche in the market is both extremely competitive and innovative, bringing new forms of access every day.

This article was prepared in the following way as explained next. After this brief introduction, a description of Multicriteria Decision Aiding methods and Prospect Theory is introduced. Next, the theory of the TODIM method is presented and some definitions related to the Internet. In the following stage, the case study is presented. The next sections discuss the results obtained and present the conclusions of this research.

\section{ANALYTICAL FRAMEWORK}

\subsection{Multicriteria Decision Aiding}

Multicriteria Decision Aiding is the field of Operational Research used when it is necessary to carry out the selection, classification, ranking or description of the possible alternatives to solve a decision problem, in the simultaneous presence of quantitative and qualitative criteria (Roy \& Bouyssou, 1993; Keeney \& Raiffa, 1993; Belton \& Stewart, 2002). In this way, bearing these 
considerations in mind, it encounters a wide range of decision problems. Thus, diverse analytical methods have been proposed and used in practice, such as the methods from the ELECTRE family (Roy \& Bouyssou, 1993); the PROMÉTHÉE II methods (Brans \& Mareschal, 2002); the AHP method (Saaty, 1990); the UTA method (Jacquet-Lagrèze \& Siskos, 1982); the UTA-CR method (Rangel, 2002; Gomes \& Rangel, 2009b); the TODIM method (Gomes \& Lima 1992a; 1992b; Gomes \& Rangel, 2009a) and the MACBETH method (Bana and Costa \& Vansnick, 1994). Some of these methods are characterised by employing the relation of outranking in their development, and, as such, are classified as methods of the French School, while others, which seek to represent a global utility function, are classified as methods of the American School. There are also others which possess characteristics of both these methods, as is the case of the TODIM method, as mentioned in Section 1 of this article. Each of these analytical methods, in general, possesses specific characteristics and axioms to solve a decision making problem.

\subsection{Prospect Theory and the TODIM Method}

Prospect Theory emerged from the joint research work of two Israeli psychologists, Daniel Kahneman and Amos Tversky, and was first published in 1979 (Kahneman \& Tversky, 1979). The objective of the research was to evaluate human behaviour during decision making and in situations of risk. These two psychologists observed that, in situations involving gains, there is a tendency for human beings to be more conservative in relation to risk, in other words, people prefer to opt for a smaller gain, which is secure, rather than running a risk to obtain a greater gain. On the other hand, in situations involving losses, people are shown to be more prone to taking risks, that is, they prefer to run the risk of greater losses (if there is the possibility of not losing anything) than to accept a smaller risk, although a secure one.

Prospect Theory uses the value function to explain aversion and propensity to risk. This function takes the form of an " $S$ ", represented in Figure 1. Above the horizontal axis, considered as the reference in this analysis, there is a concave curve representing gains, and, below the horizontal axis, there is a convex curve representing the losses. The concave part reflects aversion to risk in the face of gains and the convex part, in turn, symbolises the propensity to risk when dealing with losses.

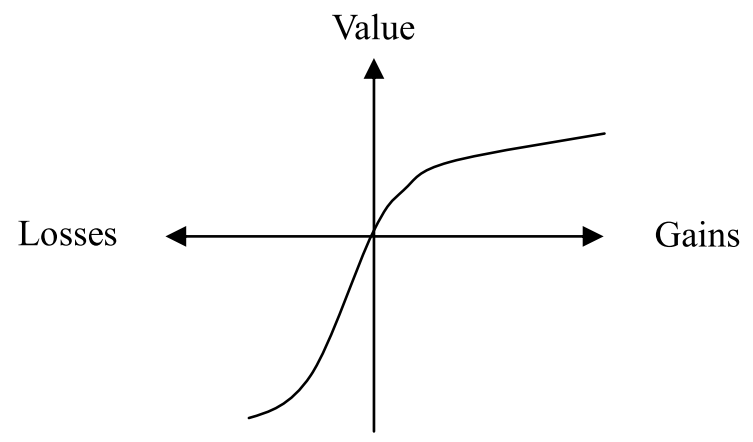

Figure 1 - The Value Function of Prospect Theory. 
The multicriteria method TODIM (acronym for TOmada de Decisão Interativa e Multicritério Interactive and Multicriteria Decision Making), conceived in its current form at the beginning of the 1990s (Gomes, Araya \& Carignano, 2004), is probably the only multicriteria method based on Prospect Theory. This means that there is definitely a theory underlying the method, a theory so strong that it partially justified the Nobel Prize for Economics been awarded to Kahneman in 2002 (Roux, 2002). The TODIM method makes use of a notion of a global measure of value calculable by the application of the paradigm of Prospect Theory. With this, the method is based on a description - already proved by empirical evidence - of how people effectively make decisions in the face of risk (Gomes, Rangel \& Maranhão, 2009; Gomes \& Rangel, 2009a).

However, so as to be able to apply this paradigm to a database arising from calculations and value judgements, the TODIM method must test specific forms of the losses and gains functions. These, once validated empirically, shall serve to construct the additive difference function of the method, which supplies measures of dominance of each alternative over the others. While it seems complicated to have to test the validity of the application of the paradigm to the database which could lead the decision analyst to use other forms of losses and gains functions - in fact, it is not, as, since the first practical uses of the TODIM method, at the beginning of the 1990s, the same mathematical forms have been used with success (in other words, validated empirically) (Gomes \& Rangel, 2009a).

From the construction of the aforementioned additive difference function of TODIM, - which functions as a multiattribute value function and, as such, must also have its use validated by the verification of the condition of mutual preferential independence - the method leads to a global ranking of the alternatives. It can be seen that the multiattribute value function - or additive difference function - of the TODIM method is constructed from a projection of the differences between the values of any two alternatives (perceived in relation to each criterion) over a referential criterion or reference criterion (Gomes \& Rangel, 2009a).

The TODIM method makes use of pair comparisons between decision criteria, having technically simple and correct resources to eliminate possible inconsistencies arising from these comparisons. It also allows judgement values to be carried out in a verbal scale, using a criteria hierarchy, fuzzy value judgements and making use of relations of interdependence among the alternatives.

The theory of the TODIM method can be verified in Gomes, Araya \& Carignano, 2004. In all applications of the TODIM method the value function that is built from problem data has the same shape of the value function of Prospect Theory. That shape is shown in Figure 1. The equations of the TODIM method that allow building its value function are presented in expression (2), (3) and (4) of this section (Gomes \& Rangel, 2009a).

Consider a set of $n$ alternatives to be ranked in the presence of $m$ quantitative or qualitative criteria. To determine the weight of the criteria, the TODIM method suggests the use of a criteria pair comparison matrix. The Saaty scale (1990) is used to construct this matrix. However, weights of criteria could also be obtained through a ratings scale, i.e. through a direct evaluation 
on a given scale. As, however, all pair comparison matrices can contain some inconsistencies, arising from the violation of transitivity, the TODIM method possesses a resource which, at the same time as it respects the judgement values which lead to the initial matrix, corrects them in a systematic way, entirely eliminating occasional inconsistencies. Once the corrected matrix of criteria pair comparisons has been constructed, the application of the TODIM method proceeds in the direction of obtaining the weights of the criteria, using for this purpose the following two stages: (i) the values are added along each column of the corrected matrix; (ii) the reciprocals of these sums are calculated; (iii) each of these reciprocals is divided by the sum of the reciprocals: the values obtained in this way will be the weights of the criteria. After the definition of these criteria weights, the specialists are asked to estimate for each one of the qualitative criteria $c$, the contribution of each alternative $i$ to the objective associated with the criterion. This method requires the values of the evaluations, of the criteria in relation to the alternatives, to be numerical and to be normalised. Therefore the qualitative criteria evaluated in a verbal scale are transformed into a cardinal scale. The use of a verbal scale, however, does not allow one to state that the pairs of consecutive degrees represent equal preference differences over the whole scale (Roy, 2005). Neverthless, the transformation of values read on a verbal scale into corresponding readings on a cardinal scale can be performed through a table of correspondences. For instance, Saaty's scale provides such correspondences (Saaty, 1990). The evaluations of the quantitative criteria are obtained through the performances of the alternatives in relation to the criteria, such as, the level of noise in decibels, the power of an engine measured in HP, a student's mark in a subject, for example (Gomes, Araya \& Carignano, 2004).

After the evaluation of the alternatives in relation to all of the criteria, the evaluation matrix is obtained, where the values are all numerical. The values are then normalised. This normalisation is carried out for each criterion, thus obtaining a matrix where all the values are between zero and one, called the matrix of partial desirabilities $P=\left[P_{n m}\right]$, as shown in Table 1 .

Table 1 - Matrix of Partial Desirabilities.

\begin{tabular}{|c|c|c|c|c|c|c|}
\hline \multirow{2}{*}{ Alternatives } & \multicolumn{6}{|c|}{ Criteria } \\
\cline { 2 - 7 } & $\mathrm{C}_{1}$ & $\mathrm{C}_{2}$ & $\ldots$ & $\mathrm{C}_{\mathrm{j}}$ & $\ldots$ & $\mathrm{C}_{\mathrm{m}}$ \\
\hline $\mathrm{A}_{1}$ & $\mathrm{P}_{11}$ & $\mathrm{P}_{12}$ & $\ldots$ & $\mathrm{P}_{1 \mathrm{j}}$ & $\ldots$ & $\mathrm{P}_{1 \mathrm{~m}}$ \\
$\mathrm{~A}_{2}$ & $\mathrm{P}_{21}$ & $\mathrm{P}_{22}$ & $\ldots$ & $\mathrm{P}_{2 \mathrm{j}}$ & $\ldots$ & $\mathrm{P}_{2 \mathrm{~m}}$ \\
$\ldots$ & $\ldots$ & $\ldots$ & $\ldots$ & $\ldots$ & $\ldots$ & $\ldots$ \\
$\mathrm{A}_{\mathrm{i}}$ & $\mathrm{P}_{\mathrm{i} 1}$ & $\mathrm{P}_{\mathrm{i} 2}$ & $\ldots$ & $\mathrm{P}_{\mathrm{ij}}$ & $\ldots$ & $\mathrm{P}_{\mathrm{im}}$ \\
$\ldots$ & $\ldots$ & $\ldots$ & $\ldots$ & $\ldots$ & $\ldots$ & $\ldots$ \\
$\mathrm{A}_{\mathrm{n}}$ & $\mathrm{P}_{\mathrm{n} 1}$ & $\mathrm{P}_{\mathrm{n} 2}$ & $\ldots$ & $\mathrm{P}_{\mathrm{nj}}$ & $\ldots$ & $\mathrm{P}_{\mathrm{nm}}$ \\
\hline
\end{tabular}

After the attribution of the weights of the criteria and their normalisation, it is necessary to calculate the matrices of partial dominance and the matrix of final dominance. It is now accepted that anyone of the $m$ criteria can be considered to be a reference criterion $r$; this might be, for example, identified as being the criterion with the greatest weight. Thus, $w_{r c}$ represents the 
substitution rate of the criterion under analysis $c$ in relation to the reference criterion $r$. The measure of dominance of each alternative $i$ over each alternative $j$, now incorporated to Prospect Theory, is given by the mathematical expression (1):

$$
\delta\left(A_{i}, A_{j}\right)=\sum_{c=1}^{m} \Phi_{c}\left(A_{i}, A_{j}\right), \forall(i, j)
$$

where:

$$
\Phi_{c}\left(A_{i}, A_{j}\right)= \begin{cases}\sqrt{\frac{w_{r c}\left(P_{i c}-P_{j c}\right)}{\sum_{c=1}^{m} w_{r c}}} & \text { if }\left(P_{i c}-P_{j c}\right)>0, \\ 0 & \text { if }\left(P_{i c}-P_{j c}\right)=0, \\ \frac{-1}{\theta} \sqrt{\frac{\left(\sum_{c=1}^{m} w_{r c}\right)\left(P_{j c}-P_{i c}\right)}{w_{r c}}} & \text { if }\left(P_{i c}-P_{j c}\right)<0,\end{cases}
$$

thus:

- $\delta\left(A_{i}, A_{j}\right)$ represents the measurement of dominance of alternative $i$ over alternative $j$;

$-m$ is the number of criteria;

$-c$ is any criterion, for $c=1, \ldots, m$;

$-w_{r c}$ is the substitution rate of the criterion $c$ by the reference criterion $r$;

- $P_{i c}$ and $P_{j c}$ are, respectively the performances of the alternatives $i$ and $j$ in relation to $c$;

$-\theta$ is the attenuation factor of losses.

The factor $\Phi_{c}\left(A_{i}, A_{j}\right)$ represents the parcel of the contribution of the criterion $c$ to the function $\delta\left(A_{i}, A_{j}\right)$, when alternative $i$ is compared with alternative $j$. If the value of $P_{i c}-P_{j c}$ is positive, it will represent a gain for the function $\delta\left(A_{i}, A_{j}\right)$ and, therefore, the expression $\Phi_{c}\left(A_{i}, A_{j}\right)$ will be used corresponding, that is, to the equation (2). If $P_{i c}-P_{j c}$ is nil, the value zero will be attributed to $\Phi_{c}\left(A_{i}, A_{j}\right)$, in other words, the equation (3), and if $P_{i c}-P_{j c}$ is negative, $\Phi_{c}\left(A_{i}, A_{j}\right)$ will be represented by the equation (4).

After the various partial dominance matrices have been calculated, one for each criterion, the final dominance matrix is obtained $\delta\left(A_{i}, A_{j}\right)$, by adding together the elements of the diverse matrices.

The final dominance matrix is then normalised, using the expression (5), to obtain the global value of each alternative. Each number calculated must be interpreted as the measure of desirability 
or global utility, or simply, as the value of a specific alternative. The ranking of the alternatives originates from the ordering of their respective values.

$$
\xi_{i}=\frac{\sum_{j=1}^{n} \delta\left(A_{i}, A_{j}\right)-\min \sum_{j=1}^{n} \delta\left(A_{i}, A_{j}\right)}{\max \sum_{j=1}^{n} \delta\left(A_{i}, A_{j}\right)-\min \sum_{j=1}^{n} \delta\left(A_{i}, A_{j}\right)}
$$

Therefore, the TODIM method determines, from the preferences expressed by a decision maker or a group of decision makers, a choice, by the ranking of all the alternatives. Changing this set of preferences, it is possible to reach a new result, through a sensitivity analysis, as discussed later on in Section 4.

\section{CASE STUDY}

\subsection{The Internet and its use in Brazil}

Currently, the Internet forms part of everyone's lives and part of the life of companies, from domestic users, through small and medium businesses to large corporations, linking the world through the worldwide computer network. The large number of Internet service providers has made the competition in this niche of the market very stiff. Naturally, as a result, consumers have benefited in various aspects, such as, for example: lower prices, greater quality of service, better customer service, among others. However, the large number of options currently encountered makes the choice on the part of the consumer difficult, as it is not the case of simple differentiation by price, but instead an immense range of varied services, leading to the need for more detailed studies for a clearer differentiation and classification of the services offered.

The Internet was conceived for military use. Due to the fear of nuclear attack, scientists created a structure of non-hierarchical access, to be able to survive in case of a cataclysm. On implementing the network in universities, this non-vertical model was maintained and with this began the creation of numerous forms of communication not initially foreseen. Everyone sought their peers, their interests (Global, 2008).

The first forecasts of the Internet date from 1962 at MIT (Massachusetts Institute of Technology), when the concept of an interconnected network of computers was created. It was a structure of non-hierarchical access capable of surviving a cataclysm. From this, the ARPANET was created which was the first network to be truly successful in data transferral between computers. Rapidly, new computers were added to the ARPANET (Global, 2008).

In Brazil, this growth has also been extremely large. In January 2008, the number of active residential Internet users was 21.1 million people, while in January 2005 it was 10.7 million users. In addition to this, the average time that each users remains on the network has also been increasing, in 2005 it was $14 \mathrm{~h} 35 \mathrm{~min}$ per month while this changed to $23 \mathrm{~h} 12 \mathrm{~min}$ per month in 2008. This increase can partially be explained by the increase in the number of homes with computers and the advent of broadband (IBOPE, 2008). 
As well as this, the number of Broadband Internet users in Brazil grew from 7.6 million in January 2006 to 10.2 million in January 2007. In 2007, this value represented $72.9 \%$ of total domestic internet access in Brazil. In six years (from 2001 to 2006), broadband in Brazil registered 5.3 million new domestic connections, a growth of 1,639\%. [10] Competition among cable TV operators and telephone operators stimulated the offer of services with greater speeds and resulted in a fall of $8 \%$ in the average price particularly in faster speed plans. In the Corporate Market in the second semester of 2006, broadband access grew by $20.8 \%$, reaching almost 100,000 dedicated connections.

At the moment, there are various internet access technologies available in the national market: (i) Dial-up access; (ii) DSL - Digital Subscriber Line; (iii) Radio; (iv) CDMA - Code Division Multiple Access; (v) Cable; (vi) GSM - Global System for Mobile Communications (GSM: originally Groupe Spécial Mobile); and (vii) 3G, for exemple (Carvalho \& Lotito, 2005; Ross, 2008).

As seen by the descriptions above, there are many Broadband Internet access technologies available nowadays. In addition to this, the diverse companies acting in the market transform these technological options, through their access plans, into innumerable options for the consumer. This makes the decision regarding which plan would be the most suitable to each group of necessities much more difficult. It was this difficulty which made this study viable.

\subsection{Description of the Problem}

A small businessman from Volta Redonda with the aim of being better prepared for increasing competition faced in the marble market intends to make significant technological changes to his company.

The marble works today has only one computer at its disposal used by the businessman's secretary. The main tasks currently performed are the budget, orders for services to be carried out and a simple form for stock control.

With the growth of sales, the need for a more robust interface of integration with the clients has also grown. The major clients today are construction companies which mainly use electronic mail to communicate with suppliers, sending requests for costing and even confirmed orders. Other clients use electronic commerce sites, where they can place orders and receive quotes.

In addition to this, the suppliers of raw materials are, in general, located at a considerable distance from the urban areas and there is the complication that the material (marble or granite) is subject to variations in its nature. For this reason, many companies which work with stone extraction currently make photographs of the material for sale available on the internet to increase confidence in purchases.

There are also programs available for use on-line which help in the management of small companies. These include, for example: stock control, supply chain management, etc. All of these are offered through Internet sites. 
These are the main reasons which have led this small businessman from Volta Redonda to invest in the purchase of three computers for his company. However, this does not make sense if these computers are not connected with each other and, principally, have access to the worldwide computer network so that the company can take advantage of new developments in the market and remain competitive.

Looking for a reliable Internet service which met his needs, the businessman was faced with a large market full of variables. Without a technique which would guarantee him a good choice of service, the businessman then asked for the help of researchers from the Universidade Federal Fluminense (Fluminense Federal University, here designated as UFF) of the University Unit of Volta Redonda, which resulted in the work of this research.

In this case study it was decided to use the TODIM method for the following reasons: (i) TODIM produces a complete order of all alternatives; (ii) TODIM is founded on Prospect Theory, which takes into consideration the risk facing attitudes of decision makers; (iii) TODIM is suitable to sensitivity analyses through variations in the parameter $\theta$; and (iv) TODIM can be used through a simple spreadsheet and therefore without the need of a commercial software.

\subsection{Development of the Research}

First of all, research was undertaken on the main Broadband Internet Technologies currently available in the market. To do this, the internet itself and the knowledge of the UFF specialists in Information Technology were used as research tools, as well as interviews with representatives of the companies which work supplying Broadband Internet access in the city of Volta Redonda. This work resulted in the data presented in Subsection 2.4 - Internet, in this article, which describes the methods of Internet access.

This preliminary research, in conjunction with a discussion with the future users of the Broadband Internet access service, enabled the preparation of a questionnaire which sought to direct the research towards the main characteristics of services of access to Broadband Internet. The requirements chosen were those considered the most relevant by the users and, also, made available by the service providers. The requirements chosen at first are described in Table 2 .

Table 2 - Preliminary Requirements.

\begin{tabular}{|l|l|}
\hline Requirements & Description \\
\hline Coverage & If the provider offers the service at the desired location \\
\hline Initial investment & Expenditure on purchase of parts for the installation of the system \\
\hline Monthly payment & Monthly payment for the service \\
\hline Speed & Speed available for the connection \\
\hline Loyalty & Minimum time that the user must subscribe to the service provider \\
\hline
\end{tabular}

Afterwards, the companies which provide Broadband Internet services in the region of interest were listed, making a total of seven different service providers. Following this, finally the field work was begun. 
In the field work, the case study was presented to the service providers in the form of personal visits, telephone contacts, or even, via the internet. In this way, the data of each of the variables presented in Table 2 was collected in relation to each of the plans made available by the service providers. It should be highlighted that the same service provider may often offer several different internet access plans. For this reason, a total of twenty Broadband Internet plans were collected, provided by only seven companies.

In addition to this, the research showed that the variables, Coverage and Loyalty, would not need to be incorporated in the method. Coverage (in spite of being an eliminatory factor, as, if there was no coverage in the location required, the company would be eliminated from the classification) was not considered because all the plans studies reached the marble works address. Loyalty was discarded because all the plans presented a loyalty period less than the expectation of the small business, as this company was planning to sign a contract of more than two years.

The need for other variables was also noted. Firstly, the speed offered by the companies in their advertisements is the maximum speed of the service, while they have a band of guaranteed connection speed, with a minimum and maximum speed. In this way, there is a need to incorporate a variable for the minimum speed and another for the maximum speed of the access plan. Secondly, it was discovered that there are various plans with a limit of use in megabytes and a rate charged for additional megabytes. Therefore, the requirements to be analysed were modified as are described in Table 3.

Table 3 - Final Requirements.

\begin{tabular}{|l|l|}
\hline Requirements & Description \\
\hline Initial investment & Expenditure on purchase of parts for the installation of the system \\
\hline Monthly payment & Monthly payment for the service \\
\hline Minimum speed & Minimum speed of connection guaranteed by the server \\
\hline Maximum speed & Maximum speed of connection guaranteed by the server \\
\hline Limit & Limit of use in Megabytes (MB) of the plan chosen \\
\hline Additional MB rate & Price per Megabytes (MB) used exceeding limit \\
\hline
\end{tabular}

Thus, the alternatives offered by the market can be analysed in accordance with the criteria collected. The seven providers of different services of Broadband Internet access, through the use of different technologies, together offer twenty different types of access to this type of service, identified as $A_{i}$, where $i$ varies from 1 to 20. Each of the alternatives received a value for the criteria as shown in Table 4.

Table 4 shows a relatively large cost difference between the services offered by broadband Internet suppliers. In order not to disregard proposals of services with quite different costs and with similarly different benefits, cost could not be treated as included in the set of evaluation criteria. As a matter of fact, the decision maker had difficulties in making judgments about the trade-off between costs and benefits. Only if our decision maker had not found such difficulties one could have treated cost as just another criteria (Goodwin \& Wright, 2000). 
Table 4 - Criteria Used.

\begin{tabular}{|c|c|c|c|c|c|c|}
\hline \multirow{3}{*}{$\begin{array}{l}\text { Alternatives } \\
\text { of the } \\
\text { Internet } \\
\text { plans }\end{array}$} & \multicolumn{2}{|c|}{ Criteria used after TODIM } & \multicolumn{4}{|c|}{ Criteria used in TODIM (Benefits) } \\
\hline & $\mathrm{T}_{1}$ & $\mathrm{~T}_{2}$ & $\mathrm{C}_{1}$ & $\mathrm{C}_{2}$ & $\mathrm{C}_{3}$ & $\mathrm{C}_{4}$ \\
\hline & $\begin{array}{c}\text { Initial } \\
\text { investment }\end{array}$ & $\begin{array}{l}\text { Monthly } \\
\text { payment }\end{array}$ & $\begin{array}{c}\text { Minimum } \\
\text { speed } \\
(\mathrm{Kbps})\end{array}$ & $\begin{array}{c}\text { Maximum } \\
\text { speed } \\
(\mathrm{Kbps})\end{array}$ & $\begin{array}{l}\text { Limit } \\
\text { (MB) }\end{array}$ & $\begin{array}{l}\text { Price per } \\
\text { additional } \\
(\mathrm{MB})\end{array}$ \\
\hline $\mathrm{A}_{1}$ & $\mathrm{R} \$ 10.00$ & $\mathrm{R} \$ 99.00$ & 130 & 144 & - & - \\
\hline $\mathrm{A}_{2}$ & $\mathrm{R} \$ 10.00$ & $\mathrm{R} \$ 69.00$ & 130 & 144 & 4000 & $\mathrm{R} \$ 0.50$ \\
\hline $\mathrm{A}_{3}$ & $\mathrm{R} \$ 389.00$ & $\mathrm{R} \$ 19.00$ & 140 & 250 & 40 & $\mathrm{R} \$ 0.25$ \\
\hline $\mathrm{A}_{4}$ & $\mathrm{R} \$ 199.00$ & $\mathrm{R} \$ 29.00$ & 140 & 250 & 250 & $\mathrm{R} \$ 0.25$ \\
\hline $\mathrm{A}_{5}$ & $\mathrm{R} \$ 99.00$ & $\mathrm{R} \$ 69.00$ & 140 & 250 & 1000 & $\mathrm{R} \$ 0.25$ \\
\hline $\mathrm{A}_{6}$ & $\mathrm{R} \$ 199.00$ & $\mathrm{R} \$ 59.00$ & 70 & 100 & 2000 & $\mathrm{R} \$ 0.50$ \\
\hline $\mathrm{A}_{7}$ & $\mathrm{R} \$ 350.00$ & $\mathrm{R} \$ 48.00$ & 50 & 100 & - & - \\
\hline $\mathrm{A}_{8}$ & $\mathrm{R} \$ 350.00$ & $\mathrm{R} \$ 78.00$ & 100 & 200 & - & - \\
\hline $\mathrm{A}_{9}$ & $\mathrm{R} \$ 350.00$ & $\mathrm{R} \$ 108.00$ & 150 & 300 & - & - \\
\hline $\mathrm{A}_{10}$ & $\mathrm{R} \$ 360.00$ & $\mathrm{R} \$ 45.00$ & 30 & 100 & - & - \\
\hline $\mathrm{A}_{11}$ & $\mathrm{R} \$ 360.00$ & $\mathrm{R} \$ 60.00$ & 60 & 200 & - & - \\
\hline $\mathrm{A}_{12}$ & $\mathrm{R} \$ 360.00$ & $\mathrm{R} \$ 90.00$ & 90 & 300 & - & - \\
\hline $\mathrm{A}_{13}$ & $\mathrm{R} \$ 60.00$ & $\mathrm{R} \$ 79.00$ & 30 & 100 & - & - \\
\hline $\mathrm{A}_{14}$ & $\mathrm{R} \$ 310.00$ & $\mathrm{R} \$ 51.00$ & 90 & 100 & - & - \\
\hline $\mathrm{A}_{15}$ & $\mathrm{R} \$ 310.00$ & $\mathrm{R} \$ 61.00$ & 135 & 150 & - & - \\
\hline $\mathrm{A}_{16}$ & $\mathrm{R} \$ 310.00$ & $\mathrm{R} \$ 77.00$ & 180 & 200 & - & - \\
\hline $\mathrm{A}_{17}$ & $\mathrm{R} \$ 310.00$ & $\mathrm{R} \$ 97.00$ & 270 & 300 & - & - \\
\hline $\mathrm{A}_{18}$ & $\mathrm{R} \$ 0.00$ & $\mathrm{R} \$ 140.00$ & 150 & 300 & - & - \\
\hline $\mathrm{A}_{19}$ & $\mathrm{R} \$ 0.00$ & $\mathrm{R} \$ 199.00$ & 300 & 600 & - & - \\
\hline $\mathrm{A}_{20}$ & $\mathrm{R} \$ 0.00$ & $\mathrm{R} \$ 299.00$ & 512 & 1024 & - & - \\
\hline
\end{tabular}

The criteria called $T_{1}$ and $T_{2}$, Monthly payment and Initial Investment respectively, were not analysed in the initial stage of the evaluation of the Broadband Internet service providers, as there was much discrepancy in these costs and they could have compromised the process of the evaluation as a whole.

For the criterion Limit $\left(\mathrm{C}_{3}\right)$ the value of 10 Gigabytes was stipulated for the unlimited plans. This value was adopted together with the decision agents, this being a very high value within the expectation of use of the service by the marble works.

In the case of the criterion Price per Additional Megabyte $\left(\mathrm{C}_{4}\right)$ the inverse of the price was used, as, if this was not done, the alternatives with the higher price would benefit to the detriment of those with a lower or no price, due to the method used. As well as this, for those alternatives which do not have limits, a sufficiently high value was used, guaranteeing that none of the alternatives would be prejudiced in the implementation of the evaluation method. In this way, the Decision Matrix was formed. This Decision Matrix displays the evaluation of the twenty alternatives, $A_{1}, A_{2}, \ldots, A_{20}$, in relation to the four criteria $C_{1}, C_{2}, C_{3}, C_{4}$, with all the criteria 
which will be used in the TODIM method already normalised, in other words, with a maximum value of 1 and a minimum of 0 .

In accordance with the importance of the criteria used in this research to classify the internet plans, their respective weights were defined by the decision agents through direct valuation, and later normalised. In this way, the normalised weights for the four criteria are: $0.34615 ; 0.26923$; 0.15385 and 0.23077 respectively. From those four criteria the one with the highest weight (i.e., criterion $\mathrm{C}_{1}$ ) was chosen as the reference criterion. Inconsistencies in obtaining the weights of criteria can only exist in the situation when these weights are obtained by pairwise comparisons as mentioned in Section 2.2. These inconsistencies are understood as violations of transitivity. When such inconsistencies are detected in pairwise comparison matrices, however, they can be easily eliminated by substituting the values in each cell of the matrix by the ratios of the first approximations to criteria weights. In cell $(i, j)$, for instance, we would substitute the value of $w_{i j}$ that was provided by the decision agent by the ratio of the initially computed weights for $i$ and $j$. We would next compute the final criteria weights, now from a fully consistent pairwise comparison matrix. By following this procedure it would not be necessary to ask for new value judgments from the decision agents as it is has been usually done when AHP is used. Besides, all possible inconsistencies would be solved in one single shot (Gomes, 1993). In the research reported in this article, however, weights of criteria were defined through direct evaluations and therefore inconsistencies were not an issue.

With the purpose of performing a sensitivity analysis of the ranking obtained, various implementations were carried out for values of $\theta$ varying from 1 to 10 . Through these implementations it was verified that the ranking obtained from the value of $\theta$ equal to 1 varies very little in relation to the others, validating the ranking obtained. After the implementation of the mathematical formulation of the TODIM method, a normalised global value of each alternative was obtained according to the equation (5).

After this first stage of the analysis, in which the ranking of the internet access plans was obtained considering the last four criteria, a new evaluation was carried out, now considering, as well as the ranking obtained by the TODIM method, the two criteria related to costs, which are: Monthly Payment $\left(\mathrm{T}_{1}\right)$ and Initial Investment $\left(\mathrm{T}_{2}\right)$.

For this, it was taken into account that the Initial Investment would be spread over the first year of the grace period of the plans and thus it would be incorporated into the value of the monthly payment for the purpose of the calculations, and afterwards this value would be normalised. In this way, adding the Normalised Global Utility to the normalised value of the Monthly Payment and Initial Investment of each alternative, the final classification was reached and, at the end, this result was normalised. This classification is shown in Figures 2 and 3.

In the second stage of the analysis, with the objective of verifying the performances in relation to the costs of the various internet access plans, the costs of Initial Investment and Monthly Payment, the cost of the Initial Investment was considered as a cost throughout the year, the same period as the grace period of the plans. In this way, for the purpose of the calculations and 
evaluation, the cost used considered the monthly cost of a plan plus a parcel referring to the cost of implementation spread across the course of the year.

The results thus can be visualised in Figure 2. This shows the optimal alternatives frontier, in other words, those which possess the greatest benefits for a given monthly payment.

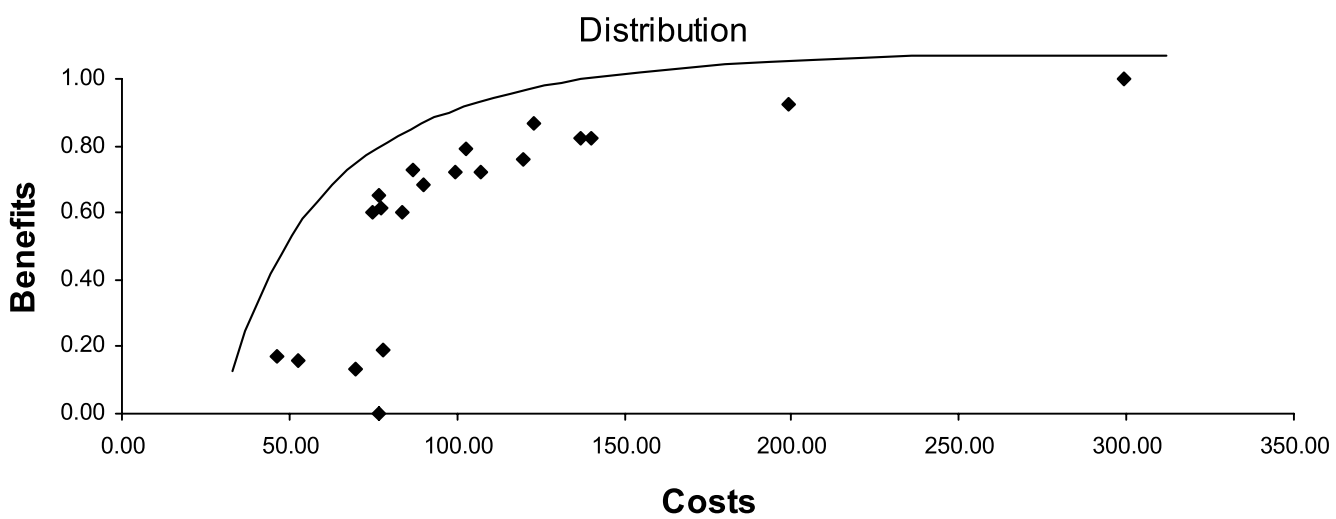

Figure 2 - Optimal Frontier.

The final ranking of the various Broadband Internet access plans is calculated considering the ranking obtained by the TODIM method of the impact of the costs of each of these plans. For this purpose, a relation between benefits, extracted from TODIM, and the costs, monthly and initial investment was obtained. This classification is presented in Figure 3. By taking into consideration that the decision maker (i.e., the owner of the small business) were prone to pay for the benefit to his firm from the Internet service to be hired, the best ratio of benefit over cost would correspond to the best alternative.

Final Classification

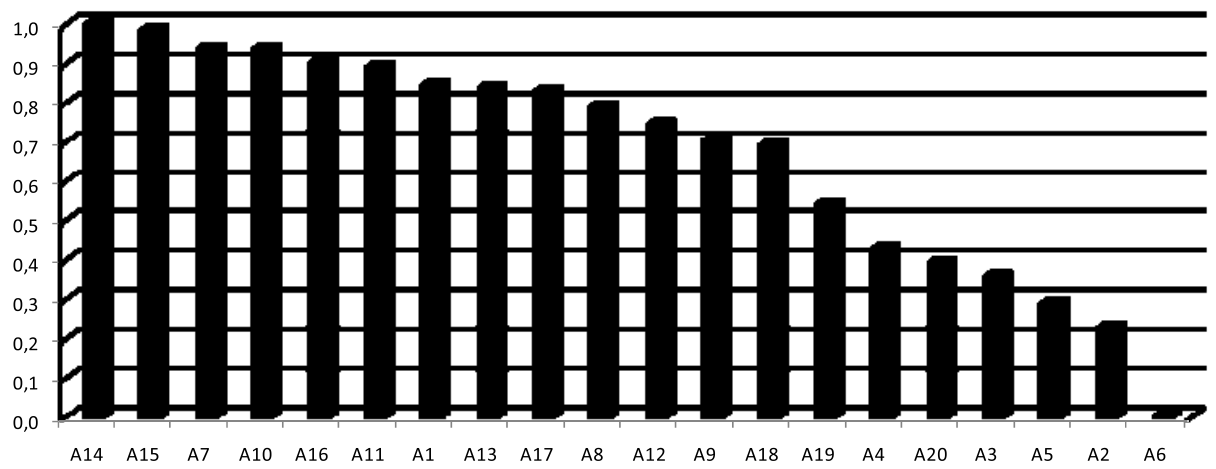

Figure 3 - Classification of the Alternatives.

Figure 3 shows the final classification of the alternatives of Broadband Internet access. From the normalised values of the Costs and Benefits, they can be related. This evaluation led to the choice of Alternative $A_{14}$, which is a package of Internet by radio with a high initial investment 
of R \$ 310.00, although it has a relatively low monthly payment of $\mathrm{R} \$ 51.00$. It is a package of unlimited access with a maximum speed of $100 \mathrm{Kbps}$ and a guarantee of $90 \%$ of the speed, in other words, its minimum guaranteed speed is $90 \mathrm{kbps}$.

\section{CONCLUSION}

The analysis of the alternatives using the TODIM method led to a ranking which was shown to be satisfactory and agreed with the expectations of the specialists. Through its formulation it becomes easier to resolve conflicts existing between the criteria, as, at times, in order to achieve a good performance in a determined analysis criterion, it is necessary to accept a lower performance in another.

In the case of evaluating the options of internet access plans, the method is capable of helping potential clients to assess the alternatives more clearly in relation to the criteria defined by the specialists and users.

Therefore, the analysis and resolution of the case study presented here, by means of a Multicriteria Decision Aiding method, the TODIM method, reflected in its results the preferences of the decision agents, in other words, of the current internet users and of the specialist knowledge holders of the multiple dimensions of the problem analysed. Consequently, it can be concluded that the method constitutes an efficient aid in the classification of service providers.

With the great speed of technological evolution we experience today, this study cannot serve as a paradigm for future decisions or, even less, stop here, as, after the publishing of this article, new technologies have entered the market and the constant research of the companies in the field of marketing brings new possibilities of access plans to consumers. This means that this study serves only as a base and guide for new research which will follow it.

\section{ACKNOWLEDGEMENTS}

The authors are grateful to the referees for their insightful comments on the first version of this paper. This work was partially supported by CNPq throught Research Projects No. 310603/20099 and 502711/2009-4.

\section{REFERENCES}

[1] Bana And Costa CA \& VAnSnick JC. 1994. MACBETH: An interactive path towards the construction of cardinal value functions. International Transactions in Operational Research, 1(4): 489-500.

[2] Belton V \& Stewart TJ. 2002. Multiple Criteria Decision Analysis: An Integrated Approach. Boston: Kluwer Academic Publishers.

[3] Brans J-P \& Mareschal B. 2002. PROMÉTHÉE-GAiA Une Méthodologie D’Aide à la Décision en Présence de Critéres Multiples. Bruxelas: Éditions de l'Université de Bruxelles.

[4] Carvalho G \& Lotito A. 2005. Tecnologias de Acesso à Internet, $1^{\mathrm{a}}$ Ed., Novatec, São Paulo.

[5] GlobAL. 2008. A Global Internet Information Provider, 2008 (www.comscore.com>, accessed on $14 / 04 / 2008)$. 
[6] Gomes LFAM. 1993. Efficient reduction of inconsistency in pairwise comparison matrices. System Analysis Modeling Simulation, 11: 333-335.

[7] Gomes LFAM, ARAYA MCG \& CARignano C. 2004. Tomada de decisão em cenários complexos. São Paulo: Pioneira Thomson Learning.

[8] Gomes LFAM \& Lima MMPP. 1992a. From Modeling Individual Preferences to Multicriteria Ranking of Discrete Alternatives: A Look at Prospect Theory and the Additive Difference Model. Foundations of Computing and Decision Sciences, 17(3): 171-184.

[9] Gomes LFAM \& Lima MMPP. 1992b. TODIM: Basics and Application to Multicriteria Ranking of Projects with Environmental Impacts. Foundations of Computing And Decision Sciences, 16(4): $113-127$.

[10] Gomes LFAM \& RANGel LAD. 2009a. An application of the TODIM method to the multicriteria rental evaluation of residential properties. European Journal of Operational Research, 193: 204-211.

[11] Gomes LFAM \& Rangel LAD. 2009b. Determining the utility functions of criteria used in the evaluation of real estate. International Journal Productions Economics, 117: 420-426.

[12] Gomes LFAM, Rangel LAD \& Maranhão FJC. 2009. Multicriteria analysis of natural gas destination in Brazil: An application of the TODIM method. Mathematical and Computer Modelling, 50: $92-100$.

[13] Goodwin P \& Wright G. 2000. Decision Analysis for Management Judgment, 2 ed. Chichester: Wiley.

[14] IBOPE. 2006. IBOPE/NetRatings, A Internet no Brasil, 2006, (www.site.abranet.org.br/_gravar/2006/05/22/1/Internetnobrasil.pdf, accessed on: 14/04/2008).

[15] JACQUET-LAGRÈze E \& Siskos J. 1982. Assessing a set of additive utility functions for multicriteria decision-making the UTA method. European Journal of Operational Research, 10: 151-164.

[16] Kahneman D \& TVersky A. 1979. Prospect theory: An analysis of decision under risk. Econometrica, 47: 263-292.

[17] Keeney RL \& Raiffa H. 1993. Decisions with Multiple Objectives: Preferences and Value Tradeoffs. Cambridge: Cambridge University Press.

[18] Rangel LAD. 2002. Determinações de funções de utilidade através das preferências dos decisores sobre o conjunto de criteria empregando o método UTA. Tese de Doutorado em Engenharia de Produção. COPPE/Programa de Engenharia de Produção, Universidade Federal do Rio de Janeiro, Rio de Janeiro.

[19] Ross AHM. 2008. Welcome to the world of cdma. CDMA Technology Resources (www.cdg.org, accessed on 14/04/2008).

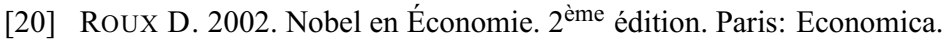

[21] Roy B. 2005. Paradigms and challenges. In: Figueira J, Greco S and Ehrgott M. (eds) Multiple Criteria Decision Analysis State of the art surveys. New York: Springer.

[22] Roy B \& Bouyssou D. 1993. Aide multicritère à la décision: méthodes et cas. Paris: Economica.

[23] SAATY TL. 1990. Decision making for leaders: the analytic hierarchy process for decisions in a complex world. Pittsburgh: RWS Publications. 